\title{
Saúde, luta de classes e o 'fantasma' da Reforma Sanitária Brasileira: apontamentos para sua história e crítica
}

\author{
Health, class struggle and the 'ghost' of the Brazilian Sanitation \\ Reform: notes for history and criticism
}

André Vianna Dantas ${ }^{1}$

DOI: 10.1590/0103-11042018S311

RESUMO O processo político da moderna Reforma Sanitária Brasileira convive, desde o seu nascedouro, nos anos 1970, com um espectro que o atormenta: o chamado 'fantasma da classe ausente', que pretende designar a pouca participação das massas populares nas lutas e reivindicações pela saúde. A experiência de participação popular do processo italiano de reforma sanitária foi a referência dos sanitaristas brasileiros, a partir da qual o estranhamento com o caso brasileiro se produziu. A história do fenômeno, no entanto, como se demonstrou, inscreve-se nos dilemas experimentados pelo conjunto da classe trabalhadora no Brasil, em franco processo de transição estratégica, no mesmo período, e se deve também às opções táticas assumidas pelos sanitaristas para a consecução dos objetivos políticos do movimento sanitário. Conclui-se que o recuo organizativo e combativo da classe é parte da derrota histórica sofrida com a derrocada do bloco socialista, na virada dos anos 1980. Sua superação só poderá ser operada pela retomada da construção da luta pela base, atravessando fronteiras setoriais e rompendo com a fetichização do Estado, como meio para a emancipação plena dos trabalhadores, e da ordem 'democrática' burguesa, como terreno 'legítimo' da luta política.

PALAVRAS-CHAVE Reforma dos serviços de saúde. Política pública. Sistema Único de Saúde.

1 Fundação Oswaldo Cruz (Fiocruz), Escola Politécnica de Saúde Joaquim Venâncio (EPSJV)

- Rio de Janeiro (RJ), Brasil. Orcid: https://orcid. org/0000-0002-10537392

andredantas@fiocruz.br
ABSTRACT The political process of the modern Brazilian Sanitation Reform has been haunted by a phantom since its beginning, in the 1970s: the so-called 'ghost of the absent class', which intends to designate the little participation of the masses in the fights and claimings for health. Brazilian sanitarists had the popular participation experience of the Italian Sanitation Reform as a reference and it was precisely from it that emerged a certain strangeness to the Brazilian case. The history of the phenomenon, however, is inscribed in the dilemmas experienced by the Brazilian working class as a whole, which was under a process of strategic transition then. It is also due to the tactical choices made by the sanitarists to achieve the political objectives of Brazilian Sanitation Movement. We conclude that the organizational and combative retreat of the class is part of the historical defeat suffered when the socialist block fell, in the turn of the 1980s. The overcoming of both the defeat and the phantom will only be accomplished through the resumption of the struggle from the base, crossing sectoral boundaries and breaking with the fetishization of the State as a means to the full emancipation of the workers; and through the restoration of the bourgeois 'democratic' order as a rightful locus of political struggle.

KEYWORDS Health care reform. Public policy. Unified Health System. 
É certo que prever significa apenas ver bem o presente e o passado como movimento.

(Antonio Gramsci)

\section{Introdução}

Momentos de balanço em perspectiva histórica costumam resultar de derrotas mais ou menos graves na luta política. Não parece restar dúvida de que seja o caso da classe trabalhadora brasileira. A energia de luta galvanizada desde a reorganização das forças populares, na luta contra a ditadura empresarial-militar (1964-1985), a partir dos anos 1970, exauriu-se de vez com o processo ativo de conciliação de classes promovido zelosamente pelos governos petistas (20032016). O golpe parlamentar de 2016 contra o governo de Dilma Rousseff marcou o fim do pacto inaugurado - já ele mesmo uma derrota - com a nova república, em 1985. A despeito de alguns sinais de retomada aqui e ali, é constatável o quanto estamos, os trabalhadores, aquém da capacidade de resistir à potência e amplitude dos ataques que viemos sofrendo, bastante agravados e intensificados desde a usurpação que levou Michel Temer à presidência da República.

É hora de inventariarmos o que produzimos em termos teóricos, práticos e programáticos na luta política emancipatória de esquerda nas últimas décadas. A análise da correlação de forças é elemento indispensável nesta escovação da história a contrapelo ${ }^{1}$, mas não pode ser debitada a ela todos os nossos fracassos. Não se trata aqui de uma perspectiva abstrata, idealista, que pretende cobrar dos projetos e das intenções políticas de determinado período a não realização, total ou parcial, de tudo o que foi declarado. $\mathrm{O}$ balanço da estratégia e das táticas assumidas na luta em processo, portanto, deve servir como ferramenta da própria luta, sem a qual a produção de mais derrotas em sequência poderá ter vida longa, pelas mesmas trilhas que, uma vez testadas, apresentam hoje mais claramente os seus gargalos, suas ribanceiras e buracos sem fundo.

Uma das expressões máximas dessa derrota tem sido o processo contínuo e, nos últimos anos, ainda mais acelerado, de desmonte do nosso Sistema Único de Saúde (SUS). Não por coincidência, foi o SUS também a política social de maior envergadura que resultou da luta pela retomada do chamado Estado Democrático de Direito. Ante o desastre, que não é de agora e cujos contornos ainda não estão inteiramente delimitados, ressurge com força o debate em torno da incômoda ausência dos trabalhadores organizados e do povo oprimido em geral das batalhas pela sua defesa. Estamos diante do célebre 'fantasma da classe ausente', na expressão cunhada por Sergio Arouca em fins dos anos 1980. Para esse importante sanitarista, e para uma geração de militantes que ao seu lado lutou por uma saúde pública, universal e de qualidade, paradoxalmente, a despeito da orientação dos seus esforços no sentido das classes trabalhadoras, o movimento sanitário quase nunca pôde contar com a sua participação direta na luta.

Para nós, não resta dúvida de que a relação dos movimentos sociais com a reforma sanitária é um nó crítico que precisamos enfrentar ${ }^{2}$ mas, diríamos, indo além, que o fenômeno que, por ora, nos ocupa atravessa as fronteiras setoriais da saúde. Tal enfrentamento também nos impõe uma avaliação da trajetória cumprida até aqui, como fizemos em estudo anterior; e não será o caso agora de recuperar por completo $^{3}$. Dividiremos este trabalho, então, em três momentos: iniciaremos pela caracterização do fenômeno; na sequência, apresentaremos a nossa crítica na intenção de contribuir para a identificação da paternidade do fantasma e, por fim, apontaremos elementos atuais indicativos da persistência das lideranças do movimento sanitário nas mesmas linhas estratégicas de ação que, ao fim e ao cabo, acreditamos, têm servido como alimento para o espectro que nos ronda. 


\section{O espectro}

Como atesta Sarah Escorel ${ }^{4(186)}$, 'fantasma da classe ausente' é a expressão que pretende designar o distanciamento dos movimentos sociais, dos trabalhadores organizados e suas instituições representativas, das lutas setoriais na saúde. Para Arouca, isso se configurava como uma limitação, à medida que expressava a incapacidade do movimento sanitário de se articular sistematicamente com esses setores e, por isso, punha mesmo em xeque a sua representatividade e legitimidade na condução da luta política do setor. Vale, no detalhe, a caracterização da própria autora:

[Arouca] chama de 'fantasma' porque 'assusta, mas não existe', ou seja, o Movimento Sanitário questiona periodicamente sua própria legitimidade enquanto intelectual coletivamente orgânico por não contemplar em suas discussões e decisões 'cotidianas' organismos formalmente representativos das classes trabalhadoras como os sindicatos operários, as centrais sindicais e até mesmo os partidos progressistas. No entanto, a classe operária não está ausente, no sentido de que seus valores e necessidades direcionam a luta pela Reforma Sanitária.

A base material do fantasma, como acreditamos e seu próprio criador parece concordar, é a crise estratégica, teórica e organizativa da classe trabalhadora desde os anos 1970/1980, em termos globais, com o fim do bloco socialista, a ascensão do neoliberalismo e a chamada reestruturação produtiva do capital. No Brasil, por uma especificidade conjuntural, a rebordosa desse desastre de grandes proporções se manifestou em uma quadra histórica de soerguimento dos movimentos de base, populares, trabalhistas, contra a ditadura. A absorção da derrota em todos os seus aspectos, sua compreensão profunda em registro nacional, algo distinto em face da energia de luta acumulada - ainda que em descenso -, e a percepção do poder do inimigo 'interno' aparentemente derrotado pelo arranjo da 'normalização democrática' eram os óbices colocados para a luta política daqueles tempos e ajudam a explicar o fenômeno, que de espectral só tem o nome.

Para tornar a equação ainda mais complexa, o que fazer diante do refluxo dos movimentos de base, populares, sindicais, combinada à chance real de fazer-se governo, por meio das eleições diretas para a presidência da República, como era o caso no ano de 1989, com a candidatura de Luís Inácio Lula da Silva, do Partido dos Trabalhadores (PT)?5. Como conceber uma sociedade civil que, em nome de uma democracia supostamente universal, reunia, no plano estrito da política, classes e frações de classe materialmente tão distintas em favor da anistia, das Diretas Já, do respeito às liberdades individuais, do fim da censura, do direito à saúde, do fim do próprio regime ditatorial? Como lidar com um Estado que, na aparência, desprivatizava-se com o retorno da democracia e poderia ser disputado de modo a cumprir as conquistas civilizatórias historicamente negadas ao povo trabalhador brasileiro?

Decerto não eram óbvias as respostas políticas a serem dadas ante uma conjuntura tão complexa. A partir desses dados de realidade e dos muitos desafios estratégicos, táticos, teóricos e programáticos que daí desdobravam, os sanitaristas tomaram opções que, ao lado da correlação de forças desfavorável, contribuíram também para o alargamento do fosso que os separavam de suas bases, reais ou pretendidas. A autocrítica em relação à absolutização da via institucional e o consequente abandono da luta construída pela base já foram realizados, em parte, pelo movimento sanitário, mas não o suficiente para desabonar a tática e abalar o lugar fetichizado da democracia - como único terreno legítimo da luta política, por excelência - e do Estado - entendido meramente como máquina a serviço dos vencedores de pleitos eleitorais. É verdadeira a constatação sobre a "ausência de partidos 
e organizações sindicais na base de apoio à reforma", mas que isso tenha "como consequência o deslocamento da luta para dentro do aparelho de Estado"6(209), é verdade apenas como opção política e elemento a ser considerado na análise, e não como relação causal, como se quer. O enfraquecimento paulatino da pujança da luta popular que explodiu nos anos 1970 e 1980 e, mais tarde, a sua quase completa retirada do cenário político a partir dos anos 1990 são, para nós, uma derrota de dupla face: imposta de fora para dentro da esquerda, mas também produzida de dentro para fora. Fomos fisgados pelo canto de sereia que nos conduziu de peito aberto para o terreno de luta dos nossos inimigos, como se fosse o nosso próprio. Nesse sentido, temos contribuído ativamente para desencarnar a classe que no minuto seguinte chamamos de 'fantasma'.

Contudo vejamos o problema mais de perto. Diante da deficiente abordagem, na saúde coletiva, da temática dos movimentos sociais e também da difícil apreensão desse objeto quando se trata de definir o grau de sua interseção com as bandeiras da saúde ${ }^{7,8}$, para abordarmos a relação das lideranças do movimento sanitário com suas bases, tomaremos como expressão representativa desses grupos o Movimento Popular em Saúde (Mops), nascido em 1981, fruto do III Encontro Nacional de Experiências em Medicina Comunitária (Enemec). Segundo a compreensão das forças populares envolvidas no processo, a formação do Mops viria em socorro da "necessidade de lutar por mudanças no modelo de assistência à saúde"9(23). No entanto, divergências quanto à pertinência política de investir na institucionalização da medicina comunitária impõem duras tensões ao recém-criado movimento. Para início de conversa, observemos, na citação a seguir, a complexidade do processo que apontamos:

O Mops já nasce 'rachado'. O pano de fundo das divergências é de cunho político geral: a radicalização das divergências fundamenta-se em 'estratégias' que opõem os militantes dos partidos (Partido dos Trabalhadores, Partido Comunista Brasileiro, Partido Comunista do Brasil) que participam do movimento. A maioria a favor do caminho da 'institucionalização' está organizada por delegados de Goiás, Sul do Pará, Mato Grosso, Zona Leste de São Paulo e Rio de Janeiro [...]. O caminho da institucionalização vai prevalecer inclusive do ponto de vista da luta democrática, como se constata na ampla aceitação pelas esquerdas, em 1984, da eleição indireta para a presidência da República, realizada por meio de um colégio eleitoral predominantemente de direita. É a 'transição pactuada' entre militares e civis9(23).

Devemos a Silvia Gerschmann ${ }^{10(70)}$ uma boa caracterização das relações difíceis entre as lideranças do movimento sanitário e o que seriam as suas bases. Para a autora, que se refere ao processo político que se deu durante a VIII Conferência Nacional de Saúde (CNS), a essência do problema se concentrava nos movimentos populares, expressos por intermédio de outra 'ausência', dessa vez de 'maturidade' para compreender e aceitar os rumos institucionalizantes da luta. De início, é possível notar certo pesar pelo abandono, por parte do Mops, do que seria uma escala evolutiva que o teria levado da posição de movimento social de base à condição de ator da disputa pelo aparelho de Estado:

Precisamente no momento em que o Mops esteve mais próximo das decisões políticas substantivas, a ausência de maturidade para absorver a institucionalização como uma exigência do processo político no setor se traduziu em cisão interna.

Na sequência, em que pese a complexidade do debate acerca da viabilidade prática de uma estatização imediata do sistema de saúde brasileiro - embora não se tratasse (ou não devesse se tratar) de um debate meramente pragmático, mas eminentemente tático -, a autora destaca o isolamento do 
Mops diante de uma proposta que ela considera irrealizável e, portanto, improcedente para aquela conjuntura:

Os delegados do Mops apresentaram uma proposta de estatização do setor, sem participação nenhuma do setor privado, a qual não contou com a aprovação da maioria das entidades representadas, dentre elas o Cebes, a Abrasco e as centrais sindicais'0(105).

Por fim, Gerschman 10(112) nos apresenta a argumentação que se encontra subjacente a toda construção de sua análise: o acerto da tática sanitarista reformista, que de tão acertada poderia seguir distante e autonomamente em relação às suas bases em potencial. É verdade, façamos justiça, que ao final do trecho citado há uma reprovação quanto à forma de condução das divergências pelas lideranças do movimento sanitário, mas nada que equilibre ou relativize o processo de institucionalização 'como uma exigência do processo político', como sacramentou a autora, expressando o posicionamento do movimento sanitário naquela conjuntura ímpar:

A mudança no terreno da luta política se explica: o Movimento Sanitário, vanguarda do processo de transformação das políticas de saúde, tinha como estratégia penetrar nos aparelhos de Estado com o objetivo de tentar implementar suas táticas para mudar a direção da política e, assim, privilegiar o setor público. [...] a participação nos organismos estatais acabou sendo uma decisão unilateral do Movimento Sanitário, o que dificultou sua relação com o Mops no transcorrer da década de 80.

O antiestatismo do Mops e, especificamente no contexto da VIII CNS, a recusa à participação do setor privado no Sistema de Saúde que se propunha, e sua consequente estatização completa, são os pontos destacados pela autora que nos permitiriam aludir ao que Lênin chamaria de 'doença infantil' daquele movimento se tivesse escrito o livro de Gerschman e endossasse a sua perspectiva. Lancemos mão ainda, mais uma vez, de Escorel11(195) para concluir esta brevíssima caracterização da tática de ouro dos sanitaristas:

A partir de 1983 o movimento sanitário conseguiu pôr em prática uma de suas estratégias, a 'ocupação dos espaços institucionais'. $\mathrm{Na}$ tentativa de modificar o direcionamento da política pública, passou a fazer das instituições de saúde um lócus de construção da contra-hegemonia. Com a adoção dessa estratégia, separou-se ainda mais do movimento popular. Ao privilegiar as instituições de saúde, relegou a segundo plano a ampliação e o aprofundamento da aliança com as classes populares e trabalhadoras [...]. O processo passou a ficar restrito a avanços e recuos no âmbito das políticas institucionais e, concentrado nesse espaço (político-legal ou jurídico-institucional) de luta, o movimento tendeu a perder de vista a necessidade de trabalhar melhor sua aliança com as classes populares.

E completa a mesma autora:

Nos primeiros anos da Nova República, o movimento sanitário viveu um ciclo de euforia quando, inserido nas instituições de saúde, conseguiu promover uma inflexão na direcionalidade da política de saúde como um todo. Esse período foi caracterizado por alguns autores como a institucionalização do movimento sanitário, que perdera a base na sociedade civil e abandonara as propostas transformadoras em favor de simples reformas administrativas. Não há dúvida de que, excetuando-se a VIII CNS e a luta na Constituinte, a atuação do movimento sanitário esteve concentrada no plano das instituições de saúde. No entanto, as duas exceções foram profundas e marcantes, atenuando as supostas tendências 'institucionalizantes'11(196).

Como é possível notar, tanto Gerschman quanto Escorel - que podem ser tomadas 
aqui como representativas da visão dominante entre os sanitaristas - apontam com preocupação o distanciamento entre as 'lideranças' do movimento e suas bases em potencial, mas tal como procedeu majoritariamente o movimento na sua compreensão de realidade, endossam a tática institucional, em última análise, por considerarem-na o centro da ação estratégica que o momento conjuntural exigia, embora acompanhada no encalço do que seria uma contingência incômoda: a ausência da base.

Giovanni Berlinguer 12(5), membro do Partido Comunista Italiano (PCI), liderança destacada da reforma sanitária daquele país e interlocutor de primeira ordem dos sanitaristas brasileiros, partindo das mesmas preocupações de Gerschman, Escorel e outros, arrisca uma brevíssima análise sobre outros dois processos históricos que resultaram na reformulação profunda dos serviços de saúde. Se na Itália a luta setorial da saúde se caracterizou pela imensa potência do movimento popular organizado, este não foi o caso não só do Brasil. Na Rússia, diz o autor, onde foi criado o serviço sanitário público nos anos imediatamente após a revolução de 1917, isso se deveu mais à "sublevação política global" do que a reivindicações populares específicas. No que diz respeito ao National Health Service (NHS) inglês, que é de 1948, Berlinguer o atribui mais à chegada dos trabalhistas ao governo e menos como produto de um movimento de massas pela saúde. A despeito de nossa maior ou menor concordância com as interpretações do autor, os casos concretos citados servem para mostrar que o fenômeno da 'classe ausente' é bem mais terreno do que se supõe, posto que indica que as lutas setoriais fazem parte de um todo indivisível que não obedece a fronteiras tão bem claras e delimitadas como pretendem muitos entre os sanitaristas.

Vale ainda um último destaque. O fim do bloco socialista, com a queda do muro de Berlim e a dissolução da União Soviética, na passagem entre os anos 1980 e 1990, e a consequente reação neoliberal burguesa são os ingredientes que permanecem na base dos processos da luta de classes até os dias atuais no mundo, embora combinados às especificidades regionais. Não é mero acaso cronológico que o auge de uma experiência como o Estado de Bem-Estar Social, no centro do capitalismo, tenha sido contemporâneo da Guerra Fria e seu desmonte comece a se dar exatamente quando o 'inimigo vermelho' vai à lona. Se para a análise das relações de força, portanto, como ensina Gramsci ${ }^{13}$, é decisivo distinguir o orgânico (movimentos relativamente permanentes) do conjuntural (ocasionais, imediatos), precisamos ter clara a curva de descenso global, desde então, da luta dos trabalhadores, a despeito de conquistas e êxitos particulares ou conjunturais. É ponto pacífico para nós, portanto, que toda análise sobre uma determinada realidade nacional deve ter em conta esta dinâmica, além de não poder descuidar dos elementos internacionais expressos em cada realidade nacional. Essa pequena digressão nos serviu aqui para reinserir o fantasma de que tratamos no mundo dos viventes.

\section{A carne e o osso}

Se retomarmos a citação de Escorel que caracteriza o objeto que ora nos ocupa, recordaremos que Arouca não compreende o tal fantasma, em verdade, como expressão da ausência absoluta da classe. Defende que a direção geral da luta pela reforma sanitária não pode ser senão da própria classe, embora o movimento e a atenção dessa mesma classe tenham estado sempre voltados em menor medida para o campo específico da saúde. Não nos parece pouco relevante essa observação, dado que indica, a nosso ver, uma compreensão dialética da realidade, em que as lutas setoriais não podem ser tomadas apenas no interior de suas fronteiras, para a compreensão tanto dos êxitos setoriais como dos dilemas e derrotas globais que se 
expressam também em cada setor. Essa perspectiva, no entanto, não foi a que prevaleceu no interior do movimento sanitário, por diversas razões, tendo sido a tônica de sua ação política e formulação, sobretudo a partir dos anos 1990, o insulamento, cuja principal consequência foi restringir-se ao debate em torno da gestão do SUS. O fantasma só fez crescer desde então, mas a interpretação do fenômeno também se apequenou, deslizando para uma culpabilização velada da classe trabalhadora pela sua própria derrota. Seu desconhecimento do SUS, sua pouca ou nenhuma consciência sanitária e o seu senso comum que valoriza o privado em detrimento do público, conjugados ao corporativismo sindical que fortalece o mercado dos planos de saúde, tornaram-se peças de acusação de uso corrente. Cobra-se do fantasma o que o fantasma não pode dar. Tais constatações, embora corretas, ignoram e desconhecem a própria base que acusam de ausente.

Eis a chave de leitura para o fenômeno. Sem pretender negar a sua validade como problema, é nossa intenção mapear os seus contornos e dividir as responsabilidades. A autocompreensão do setor saúde na relação com as lutas da classe trabalhadora em geral, a percepção de sua importância na luta contra a ditadura, a memória das conquistas que protagonizou e a autoproclamação como "campo privilegiado da luta de classes"4(183) - mais autoelogiosa e individualizante do que unitária e aglutinadora - têm funcionado, paradoxalmente, como um obstáculo à construção de laços, pontes, alianças e, em última análise, enraizamentos na base. É Sônia Fleury14(195) quem confirma o nosso diagnóstico: "nós fizemos uma luta muito específica e muito sem articulação com as outras áreas".

Souza $^{8}$, em uma tentativa de responder o que são, como se constituem e como atuam os movimentos de saúde, concluiu por sua imensa diversidade e, por consequência, grande dificuldade de apreensão. A intersetorialidade, aponta, é uma das características mais claramente identificáveis nos movimentos: a questão da saúde pode ser considerada, dentro dos movimentos, seja como um objetivo exclusivo, seja, ao contrário, como uma luta vinculada a várias outras ${ }^{8(50)}$.

O SUS, portanto, é produto da luta dos trabalhadores, embora não majoritariamente tenham empunhando a sua bandeira. Combinado a isso, contou significativamente, claro, o conhecimento técnico-político e a presença de militantes e profissionais do setor em posições-chave em âmbito acadêmico e governamental, mas não de modo a perder de vista - como se faz - a origem da energia que redundou no SUS. Apontar para a ausência da classe, compreendida apenas como movimento social setorial - mesmo que com a melhor das intenções políticas - desqualifica a luta e supervaloriza os arranjos pelo alto.

Outro importante ingrediente que pode ajudar a explicar o fantasma diz respeito à pretensão de pureza do movimento sanitário quanto à união nacional que seria possível forjar ante as bandeiras civilizatórias da saúde. A aposta em um projeto nacional, incluindo setores da burguesia, no sentido da construção tardia, no Brasil, de um Estado de Bem-Estar Social, é a base para entendermos o lugar da reforma sanitária nesse projeto e, no conjunto da esquerda, os seus descaminhos. Não é de ninguém senão de Sergio Arouca a sua expressão mais clara, proferida nada mais nada menos do que na sessão de abertura da célebre VIII CNS15(39):

Há alguns dias atrás, algumas entidades ligadas ao setor privado se retiraram da Conferência [...]. Mas eu lamento profundamente a sua ausência, porque nesta Conferência está se tratando é de criar um projeto nacional que não pretende excluir nenhum dos grupos envolvidos na prestação de serviços, na construção da saúde do povo brasileiro. Assim, a eles queria deixar uma mensagem: que, mesmo na sua ausência, vamos estar defendendo os seus interesses, desde que estes não sejam os interesses da mercantilização da saúde. 
Portanto, todo aquele empresário que está trabalhando seriamente na área da saúde, na qualidade da sua competência técnica e profissional, não precisa se sentir atemorizado, porque aqui ele vai ser defendido.

A saúde como campo privilegiado da luta de classes combina-se, sem crises, aos olhos do movimento sanitário, com a percepção do setor saúde em posição superior, acima do conflito entre as classes. A unidade em torno de um projeto de nação não fazia claras distinções dessas fronteiras, consideradas em vias de superação em um terreno supostamente democrático e universal ou combináveis em um possível jogo de ganha-ganha. Eis as táticas consequentes ao projeto e à leitura de realidade dos sanitaristas:

o Movimento Sanitário fez valer uma de suas outras características que é o estabelecimento de alianças com setores progressistas, populares ou não, comprometidos com a luta. $\mathrm{O}$ que Ihe permitiu consolidar alianças, manter-se enquanto movimento orgânico e organizado, foi 'conceber a unidade como valor estratégico' e tratar a questão da saúde como questão nacional 4(186).

Teixeira e Mendonça ${ }^{6(206)}$ são ainda mais diretas: "o movimento sanitário preservou sempre seu caráter suprapartidário e policlassista, condição essencial para manutenção da unidade política".

A resposta mais comum a essa crítica já abordamos algumas páginas atrás: a via institucional teria sido o caminho que restou diante da desmobilização popular em torno da reforma sanitária. A analogia imediata que está sugerida é com o caso italiano, em que a reforma sanitária, como se sabe, contou não só com uma classe numerosa e mobilizada em torno das bandeiras da saúde (mas não só) como também com o enraizamento popular do PCI, que conduziu a luta. É Jaime A. Oliveira ${ }^{\mathbf{1 6 ( 2 0 )}}$, estabelecendo uma comparação Brasil-Itália, quem nos socorre: a ideia de 'Reforma Sanitária' é pensada, na Itália, desde o início, como algo que não se restringe aos limites de um projeto de hegemonia 'burguês'. Mas sim como algo que visa superá-lo, no sentido dialético rigoroso do termo.

Insistamos um pouco na comparação. É conhecida a forte presença de militantes do Partido Comunista Brasileiro (PCB) no movimento sanitário, a começar pelo próprio Arouca $^{17}$. O projeto conciliador de classes liderado por esse partido, expresso na sua Estratégia Democrático-Nacional (EDN), que pressupunha a existência de uma burguesia interessada em um desenvolvimento nacional que pudesse retirar o País da condição subjugada em relação às potências imperialistas e superar o atraso representado pela aristocracia agrária, guiou as pretensões políticas e as leituras de realidade do movimento sanitário ${ }^{3}$, como acabamos de notar. Em profunda crise interna, que desembocaria, em 1992, no seu desmantelamento, o PCB adotou postura acanhada e conservadora durante a chamada 'transição democrática', produzindo a contenção do movimento sindical, por temor de um retrocesso autoritário do processo de distensão do regime. Por essa razão, colocou-se contra a criação do PT e da Central Única dos Trabalhadores (CUT), distanciando-se assim do movimento de massas, sindical e popular, que renascera a partir dos anos $1970^{2}$. Como atesta Stotz ${ }^{2(4)}$ :

o movimento da reforma sanitária, contudo, desenvolveu-se à margem do movimento operário, tendo inclusive abandonado uma alternativa de enraizamento operário proposto com a criação do Departamento Intersindical de Estudos e Pesquisas de Saúde e dos Ambientes de Trabalho - Diesat, fundado em agosto de 1980. Optou por manter-se dentro da coalizão política (Aliança Democrática) que promovia, sob hegemonia burguesa, a transição do poder dos militares para os civis. Foi também o que propiciou a participação dos quadros do PCB e de sua área de influência no governo do general 
Figueiredo, por meio do Conasp - Conselho Consultivo de Administração de Saúde Previdenciária, em 1981.

É difícil não elencar esse enfraquecimento acelerado da identidade do PCB na classe trabalhadora como um dos elementos que ajudam a explicar a ausência da mesma classe das lutas específicas da saúde, tão reclamada pelas lideranças sanitaristas. A frágil base social do movimento sanitário, ao contrário do que poderia fazer supor a VIII CNS, expressa-se, por exemplo, no fato de que a emenda popular da saúde angariou pouco mais de 50 mil assinaturas, enquanto as emendas favoráveis à reforma agrária e ao ensino público conseguiram juntas quatro milhões de assinaturas ${ }^{18}$. E se era já frágil no setor saúde, logo no momento seguinte se enfraqueceu também toda a mobilização e capacidade de organização social que tinha se acumulado na luta contra a ditadura.

Para conseguirmos captar essa profunda transformação, em pleno curso, do que chamamos de sociedade civil e, em associação direta, do Estado e da democracia, é urgente que voltemos a tentar compreender em profundidade a dinâmica capitalista no Brasil e as formas políticas que por aqui o processo de acumulação tem produzido. A resposta do capital à energia da luta popular dos anos 1970 e 1980 tem sido uma intensa campanha antiestado como forma de atingir tudo o que soe como público, emancipatório ou socializante. Na esteira da propalada ineficiência, corrupção e gigantismo da máquina pública, tem entrado pesadamente em cena a expansão seletiva de uma sociedade civil dita 'do bem', incolor e inodora, reduzindo o debate democrático e as lutas democratizantes a aspectos meramente gerenciais. A política praticada pelos trabalhadores e por suas lideranças (in memoriam), cada vez mais marcada pela distância de suas formas classistas, tem sido chamada pelas forças do capital a legitimar a sua própria inserção subalternizada $^{19}$. A agenda de apassivamento (ou fantasmagorização, se preferirmos) da luta organizada dos trabalhadores não é nova para a burguesia, como sabemos.

O abandono, pelas forças de esquerda mais representativas, de bandeiras antirregime, que pretendem ir além do 'existente', tem sido, a um só tempo, causa e consequência do nosso desarme quando se trata de entender em profundidade as formas clássicas de dominação burguesa, que atravessam temporalidades e conjunturas, na relação com as especificidades de cada espaço-tempo histórico. Entender e combater a apatia e a desmobilização dos trabalhadores hoje, no Brasil, passa, portanto, pela reavaliação das apostas 'democráticas' que temos feito e suas possibilidades de realização concreta.

Se debelar o fantasma não pode ser apenas obra do nosso desejo, ao menos podemos parar de alimentar toda e qualquer aura de mistério que insistir em pairar ao seu redor. Recusemos a equação ilógica que atribui nossas derrotas (setoriais ou não) à falta de povo e nossas vitórias à luta institucional. Dito de outra forma, não é possível associar as conquistas na Saúde, bem como suas crises e seus fracassos, à existência ou não de movimentos populares organizados em torno das bandeiras da saúde. Embora, no Brasil, os movimentos sociais nunca tenham fortemente se organizado por essa demanda, a única explicação razoável e historicamente correta, como atestou Arouca, é que a força do movimento organizado da classe é autora do SUS e das conquistas dos últimos 40 anos. A expertise, o conhecimento profundo das questões de saúde, a capacidade formuladora e habilidade política dos sanitaristas se beneficiaram do ambiente de luta política do período. Essa equação não pode ser invertida, posto que a ordem dos fatores, nesse caso, alteraria o produto. O desmonte do SUS é resultado do desmonte da classe e de sua luta organizada, na Saúde ou fora dela. É tarefa do movimento sanitário sair em busca da classe que sugere 'ausente' fora do estreito campo da saúde e da institucionalidade do Estado 
e da academia para, com ela, e a partir dela, produzir luta política em nome de pautas tão abrangentes e necessárias quanto as mazelas profundas que experimentam os trabalhadores atualmente.

\section{Considerações finais}

A superação de uma estratégia de classe não é mero ato de vontade das bases ou de suas lideranças, sabemos. O processo é longo, tortuoso e não tem desfecho infalível, previsível. No entanto, a identificação do descompasso entre os movimentos concretos da classe e as leituras de realidade dos que são ou se pretendem como suas lideranças é ato de vigília constante que nos cabe a todos, posto que se constitui em parte importante do nosso 'inventário'. Dessa forma, aqui neste esforço final de análise, queremos sugerir algumas rápidas pistas que indicam, no plano do discurso, a persistência das mesmas práticas políticas e apostas estratégicas, que são expressão 'também' da nossa derrota e apatia atuais.

Nesse sentido, se estivermos corretos na interpretação dos fatos, as jornadas de junho de 2013 representaram a explosão de uma concertação social vigente, mais notadamente, desde 1988 (em nome de um projeto de nação, com ampliação de direitos, à esquerda; mas sob controle, posto que 'lento, gradual e seguro', à direita) que, crescentemente, retirou das ruas e do controle das massas o exercício direto da política. Sua crise terminal foi a consequência mais visível do processo de garroteamento dos canais institucionais de atendimento às demandas populares, que Felipe Demier ${ }^{20}$ tem chamado de 'democracia blindada'. A reação ao agravamento da crise econômica e à precariedade dos serviços públicos básicos superou a até então eficiente contenção do movimento sindical e dos movimentos sociais produzida pelos governos petistas. Mesmo que débeis teórica e organizativamente, carentes de projeto e programa, as portentosas manifestações de rua de junho, suspeitamos, produziram energia concentrada suficiente para importantes desdobramentos políticos que ainda podem se concretizar em futuro breve (a conferir). Seu caráter multitudinário e espontâneo, distante de centrais, sindicatos e partidos, desafia a nossa compreensão, mas também indica com certo grau de clareza uma recusa a formas e conteúdos políticos que dirigiram o último ciclo político desde a chamada 'redemocratização’. Como nos ensina Gramsci21(190):

As classes inferiores, estando historicamente na defensiva, não podem adquirir consciência de si a não ser por negações, através da consciência da personalidade e dos limites de classe do adversário: mas justamente este processo ainda é informe, pelo menos em escala nacional.

Não nos parece adequado, portanto, que cobremos dessa irrupção recente um estágio de consciência de classe avançado que ela não poderia parir ou expressar, uma vez que a sua própria ocorrência tardia, e no formato que assumiu, nos sugere a trajetória de recuo de consciência cumprida até aqui. Todavia, ela parece nos indicar o fechamento de um período da história política brasileira, perante o esgotamento das formas institucionais e da crise dos modos consagrados de produzir a política na relação entre as classes. As evidências desse processo abundam, e as consequências para os trabalhadores - desabituados ao enfrentamento e redescobrindo, no susto, a luta de classes - têm alcançado níveis dramáticos. Como principal operadora política do ciclo que parece se fechar, as forças dessa fração majoritária da esquerda, que se autointitula 'democrática', literalmente não acusou o golpe e se mantém firme na aposta de soluções consensuadas, intraclasses, conciliadoras, universais e no estrito respeito dos limites da ordem do capital.

Não será preciso muito esforço para evidenciar, em registro atualíssimo, o que 
estamos afirmando. Basta que avancemos na caracterização desse descompasso, trazendo para o diálogo um dos mais importantes intelectuais coletivos que falam em nome do movimento sanitário e que costuma evocar o fantasma para a construção dos seus diagnósticos sobre as mesmas derrotas que têm nos atingido a todos, trabalhadores: o Centro Brasileiro de Estudos de Saúde (Cebes), criado em 1976. Em três documentos recentíssimos, essa entidade manifestou a força viva de uma prática política que resiste, como dissemos, a despeito (e na contramão) da pedagógica realidade que vivemos. Vejamos.

Em editorial intitulado 'Saúde é democracia: ontem, hoje e sempre', presente na edição de outubro de 2017, o Cebes reafirma a sua luta pela democracia e reivindica o seu importante e representativo papel nas lutas de décadas atrás pelo direito universal à saúde. Faz da realidade o seguinte diagnóstico: vivemos atualmente, em escala mundial, o aumento da tensão entre democracia e capitalismo, que anuncia o fim do 'capitalismo democrático', produto do pacto social do pós-guerra cujo resultado foi a domesticação dos mercados pela democracia. E completa:

a democracia passou a ser dominada pelos mercados, alterando o contrato social do pós-guerra e o equilíbrio que se mantinha entre os interesses do capital e os interesses dos cidadãos 22(991).

Na edição seguinte da mesma revista, que veio a público em janeiro de 2018, outro editorial, sob o título 'Justiça social, democracia com direitos sociais e saúde: a luta do Cebes', insistiu na mesma linha. Recusando o Estado, em última análise, como garantidor da relação de dominação e extração de valor que é o capital ${ }^{23}$ e romantizando a sociedade civil como o espaço do consenso e da harmonia ${ }^{24}$, o Cebes novamente nos oferece a sua compreensão do real e um programa a ser buscado pelas forças progressistas. Após um rápido balanço da trajetória cumprida até aqui na luta pelo SUS e dos constantes ataques sofridos desde 1988, com a enorme ampliação do setor privado e consequente enfraquecimento do setor público, aponta-se para a necessidade de construção de "uma sociedade solidária e democrática" na qual se deve buscar "um modelo de Estado onde políticas sociais protegem os cidadãos e reduzem as desigualdades”. Em suma, “um Estado democrático cujo centro para o seu desenvolvimento sejam as pessoas e as populações, e não os interesses do mercado"25(6).

$\mathrm{O}$ terceiro documento a que faremos referência é a tese do Cebes para o biênio 2017201926. Lançada em fins do mês de julho de 2018, com a assunção de uma nova diretoria, trata-se de um guia geral da ação política do Centro no período. No entanto, não foge às compreensões e diretrizes que apontamos aqui nos documentos anteriores e, inclusive, os repete em determinado conjunto de formulações e ideias-força. Consideramos desnecessário citá-lo diretamente para a coleta de mais evidências, mas a decisão de incluí-lo nessas considerações finais se deveu à importância estratégica conferida a ele por seus autores para a condução política do Centro, e do movimento sanitário, no próximo biênio.

Sendo assim, a perspectiva da conciliação de classes, que acredita na possibilidade de harmonização dos interesses entre capital e trabalho, no controle do capital pelo Estado - este conduzido democraticamente pela vontade geral do conjunto da cidadania -, não poderia ser mais persistente. Em que pese a importância de reafirmar a luta pela democracia sob uma conjuntura de cassação de direitos e desrespeito flagrante aos mínimos espaços de garantia legal no interior da ordem burguesa, a constatação que salta aos olhos é que continuaremos a produzir uma fantasmagoria voluntária. É de se notar que após 32 anos a síntese do programa político da esquerda democrática, vocalizado por Arouca na abertura da VIII CNS de 1986, continue a se fazer ouvir.

Em texto de 1993, analisando o impacto 
da atmosfera revolucionária dos anos 1960 e 1970, no Brasil, Jacob Gorender27(14) disse tratar-se também de um fantasma a herança deixada pela derrota da luta guerrilheira: "o fantasma da revolução brasileira”. É irresistível a analogia. Serão distintos os fantasmas? Acreditamos que não, posto que ambos são produto de derrota. Na sequência do fim do regime ditatorial, a 'esquerda democrática' que resultou do movimento de massas, embora tenha nascido recusando a conciliação de classes capitaneada pelo PCB de então, aos poucos também se afastou, convicta, da revolução e junto dela, acreditava, do seu fantasma vermelho. Elegeu a 'radicalização da democracia' como nova bandeira, nos limites da ordem burguesa e de suas instituições, na expectativa de que acumulando forças por meio de reformas, tijolo por tijolo, estaria construindo o socialismo (democrático), que viria como consequência lógica de um potente processo de democratização. Para tanto, e exatamente em função dessa estratégia, aderiu taticamente a uma forma de fazer política que, em nome das conquistas eleitorais e institucionais, crescentemente, relegou a segundo plano a organização e a mobilização pela base, produzindo assim, no que lhe coube, deliberadamente, mais distanciamento e ausência do que a correlações de forças já nos impunha. À classe que deixamos de enxergar como verdadeiro motor das conquistas civilizatórias e que, depois de desabonada pelas suas experiências mais radicais, recolheu-se, demos o nome impróprio de fantasma. É chegada a hora de reencarná-la.

\section{Referências}

1. Benjamin W. Walter Benjamin - obras escolhidas. São Paulo: Brasiliense; 1994. v. 1.

2. Stotz E. "O fantasma da classe ausente": apontamentos para um ensaio sobre o movimento da reforma sanitária. 2018 [acesso em 2018 jul 7]. Disponível em: http://www.encontraponto.prosaeverso. net/visualizar.php?idt=6360830.

3. Dantas AV. Do Socialismo à Democracia: tática e estratégia na Reforma Sanitária Brasileira. Rio de Janeiro: Fiocruz; 2017.

4. Escorel S. Saúde: uma questão nacional, In: Teixeira SF, organizadora. Reforma Sanitária: em busca de uma teoria. São Paulo: Cortez, Rio de Janeiro:
Abrasco; 2006. p. 181-192.

5. Iasi ML. As metamorfoses da consciência de classe - o PT entre a negação e o consentimento. São Paulo: Expressão Popular; 2006.

6. Teixeira SF, Mendonça MH. Reformas sanitárias a Itália e no Brasil: comparações. In: Teixeira SF, organizadora. Reforma Sanitária - em busca de uma teoria. São Paulo: Cortez, Rio de Janeiro: Abrasco; 2006. p. 193-232.

7. Ribeiro L. Os movimentos sociais e sua relação com a questão da saúde. Cadernos de Saúde Pública. jul-set 1989; 5(3):264-275. 
8. Souza LR. Movimentos de saúde: dificuldades à sua apreensão. Saúde debate. fev 1990; (29):48-51.

9. Stotz E. A educação popular nos movimentos sociais da Saúde: uma análise de experiências nas décadas de 1970 e 1980. Trabalho, Educação e Saúde. 2005; 3(1):9-30.

10. Gerschman S. A democracia inconclusa - um estudo da Reforma Sanitária brasileira. Rio de Janeiro: Fiocruz; 2004.

11. Escorel S. Reviravolta na Saúde - origem e articulação do movimento sanitário. Rio de Janeiro: Fiocruz; 1999.

12. Berlinguer G. Uma reforma para a saúde, In: Berlinguer G, Teixeira SF, Campos GWS, organizadores. Reforma Sanitária - Itália e Brasil. São Paulo: Hucitec; 1988. p. 1-106.

13. Gramsci A. O leitor de Gramsci. Rio de Janeiro: Civilização Brasileira; 2011.

14. Fleury S, Bahia L, Amarante P, organizadores. Saúde em Debate: fundamentos da reforma sanitária. Rio de Janeiro: Cebes; 2008.

15. Anais da 8. Conferência Nacional de Saúde. Brasília, 1986. Brasília, DF: Centro de Documentação do Ministério da Saúde, 1987.

16. Oliveira JA. Reformas e reformismos: para uma teoria política da Reforma Sanitária (ou, reflexões sobre a Reforma Sanitária de uma perspectiva popular). In: Costa NR, Minayo MCS, Leitão C, et al, organizadores. Demandas populares, políticas públicas e saúde. Petrópolis: Vozes; Rio de Janeiro: Abrasco; 1989. p. 13-44. v. 2.

17. Fleury S. Depoimento. 14 abr. 2005 [acesso em 2018 jul 19]. Disponível em: http://www.memoriasocial. pro.br/linhas/arouca/.

18. Rodriguez Neto E. Saúde - promessas e limites da Constituição. Rio de Janeiro: Fiocruz; 2003.
19. Fontes V. A democracia retórica: expropriação, convencimento e coerção, In: Matta GC, Lima JCF, organizadores. Estado, sociedade e formação profissinal em saúde - contradições e desafios em 20 anos de SUS. Rio de Janeiro: Fiocruz; 2008. p. 189-226.

20. Demier F. Da ditadura bonapartista à democracia blindada, In: Mattos MB, organizador. Estado e formas de dominação no Brasil contemporâneo. Rio de Janeiro: Consequência; 2017. p. 67-101.

21. Gramsci A. Cadernos do Cárcere. Rio de Janeiro: Civilização Brasileira; 2007. v. 3.

22. Costa AM, Souto L, Rizzoto ML. Saúde é democracia: ontem, hoje e sempre. Saúde debate. out-dez . 2017; 41(115):991-992.

23. Marx K. O capital - crítica da economia política (livro 1, volume 1). Rio de Janeiro: Civilização Brasileira; 2008. v. 1.

24. Fontes V. Hegemonismos e política - que democracia? In: Mattos MB, organizador. Estado e formas de dominação no Brasil contemporâneo. Rio de Janeiro: Consequência Editora; 2017. p. 207-236.

25. Rizzoto MLF, Costa AM, Lobato LVC. Justiça social, democracia com direitos sociais e saúde: a luta do Cebes. Saúde debate. jan-mar. 2018; 42(116): 5-7.

26. Centro Brasileiro de Estudos de Saúde. Cebes na luta: transformar e radicalizar a democracia para assegurar direitos sociais e saúde (tese 20172019). 21 jul. 2018 [acesso em 2018 jul 30]. Disponível em: http://cebes.org.br/2018/07/tese-do-cebes-2017-2019/.

27. Gorender J. Apresentação - Anos de chumbo: criativos e funestos, In: Ridenti M. O fantasma da revolução brasileira. São Paulo: Unesp; 1993. p. 11-14.

Recebido em 31/07/ 2018

Aprovado em 09/08/2018

Conflito de interesses: inexistente

Suporte financeiro: não houve 